\title{
IDEOLOGIAS DO CAPITAL HUMANO E DO CAPITAL SOCIAL: DA INTEGRAÇÃO À INSERÇÃO E AO CONFORMISMO
}

\author{
HUMAN CAPITAL AND SOCIAL CAPITAL IDEOLOGIES: FROM INTEGRATION TO INSERTION \\ AND CONFORMISM
}

Vânia Cardoso da Motta ${ }^{1}$

Resumo Este artigo analisa as alterações operadas nas abordagens de políticas públicas para os países de 'capitalismo dependente', na virada do século, conduzidas pelos principais organismos multilaterais e materializadas nas 'políticas de desenvolvimento do milênio' (PDMs). Identifica-se que neste conjunto de políticas foram introduzidas novas bases ideológicas calcadas na 'teoria do capital social' de Robert Putnam. No âmbito da educação, compreende-se que esse processo de ajuste vai deflagrar uma nova etapa de rejuvenescimento da ideologia do capital humano que alarga as atribuições da escola e restringe a dimensão política que insere a ação pedagógica. A tese apresentada é que as PDMs são mecanismos de hegemonia de função de direção intelectual e moral, com ações concretas e definições de metas focadas nas camadas de trabalhadores 'excluídos' do processo produtivo, mas que ainda possuem condições produtivas, com a finalidade de instaurar um processo mais intensivo de educar para o conformismo. Toma-se como base de análise categorias de Gramsci.

Palavras-chave capital humano; capital social; ideologia; conformismo; políticas públicas.
Abstract This article analyzes the changes the main multilateral agencies made, in the turn of the century, to the public policy approaches in countries where there was 'dependent capitalism,' changes materialized in the 'millennium development policies' (MDP). It is noticeable that new ideological bases, underpinned by Robert Putnam's 'social capital theory,' were introduced in these policies. In the realms of education, it is thought this adjustment process will trigger a new stage of renewal of the human capital ideology, one that increases the attributions of the school and limits the political dimension that inserts pedagogic action. The thesis is that the MDPs are intellectually- and morally-driven function hegemony mechanisms, with concrete actions and goal definitions focused on the tiers of workers who are 'excluded' from the productive process but, nonetheless, are still able to produce, aiming to establishing a more intensive process of educating for conformism. The Gramsci categories are used as a base for the analyses.

Keywords human capital; social capital; ideology; conformism; public policies. 


\section{Introdução}

O processo de globalização da economia revelou-se no limiar da virada para o novo milênio imanentemente problemático pelas conseqüências sociais que deflagrou, principalmente, mas não exclusivamente, nos países de 'capitalismo dependente'. O regime de acumulação do capital introduzido predominantemente a partir dos anos 70, que combina a hipertrofia financeira, 'doutrina' neoliberal e o novo padrão tecnológico de produção e organização do trabalho, provocou mudanças substanciais que resultaram no aumento da pobreza, do desemprego e do subemprego e na precarização do trabalho. O quadro de tensões que se constituiu nos últimos anos da década de 1990, provocado pela série de crises econômicas e pelo elevado custo social, deflagrou uma onda de movimentos sociais antiglobalizantes que se estendeu por vários países.

Setores dominantes concluíram que esse quadro de tensões colocaria em risco a coesão social e o equilíbrio internacional e que a manutenção deste tipo de regime de acumulação, na virada para o novo milênio, demandaria mecanismos de intervenção extra-econômicos. Formou-se, então, um consenso entre os intelectuais orgânicos do capital sobre a forma dogmática pela qual o FMI e o Banco Mundial impuseram a ideologia do 'livre' mercado aos países periféricos. E que o FMI, ao determinar que os países 'em desenvolvimento' abrissem seus mercados e ao provê-los de recursos para resolver suas crises de curto prazo, tornou-se parte do problema, mais do que sua solução (Schwartzman, 2004).

Com a perspectiva de criar as condições necessárias à produção e à reprodução do capital na virada do milênio, a partir de finais da década de 1990 foram introduzidos outros mecanismos de ajuste político expressos nas 'políticas de desenvolvimento do milênio' (PDMs). Neste conjunto de políticas foram introduzidas novas bases ideológicas calcadas na 'teoria do capital social' de Robert Putnam. No âmbito da educação, compreende-se que esse processo de ajuste vai deflagrar uma nova etapa de rejuvenescimento da 'teoria do capital humano' (Frigotto, 1998), ao incorporar elementos da 'teoria do capital social'.

A tese que permeia este estudo² é a de que as 'políticas de desenvolvimento do milênio' são mecanismos de hegemonia de função de direção intelectual e moral, com ações concretas e definições de metas focadas nas camadas de trabalhadores 'excluídos' do processo produtivo, mas que ainda possuem condições produtivas, para instaurar um processo mais intensivo de educar para o conformismo ${ }^{3}$.

No âmbito deste artigo, objetiva-se analisar os ajustes elaborados na 'teoria do capital humano' a partir da década de 1990, com o deslocamento da 'função econômica de integração' para a 'função econômica de inserção' 
atribuída à educação escolar, até a virada no milênio, com a inserção da 'teoria do capital social' como nova etapa de rejuvenescimento da ideologia do capital humano.

Na primeira parte será examinado o deslocamento elaborado na 'teoria do capital humano' com a inserção de novas bases ideológicas para legitimar a implementação das políticas neoliberais, indicando o processo de desgaste dessas bases em meados dos anos 1990. Na segunda parte serão indicados elementos da 'teoria do capital social' e como os organismos multilaterais incorporaram e criaram consensos com base nesta 'teoria' como uma saída para a 'crise de hegemonia do neoliberalismo'. Finalizando, será analisado o encaminhamento da ideologia do capital social como uma política voltada para dar condições de reprodução do capital na virada do milênio.

\section{Ideologia4 do capital humano: educar para o desemprego}

A 'teoria do capital humano' foi incorporada na teoria econômica moderna por Jacob Mincer e popularizada por Schultz e Becker nas décadas de 1950 e 1960. A idéia fundamental da teoria é que o trabalho, mais do que um fator de produção, é um tipo de capital: capital humano. Esse capital é tão mais produtivo quanto maior for sua qualidade. Essa qualidade é dada pela intensidade de treinamento científico-tecnológico e gerencial que cada trabalhador adquire ao longo de sua vida. A qualidade do capital humano não apenas melhora o desempenho individual do trabalhador - tornando-o mais produtivo - como é um fator decisivo para gerar riqueza, crescimento econômico do país e de equalização social.

Para esta 'teoria', nas palavras de Frigotto, “a educação potencializa trabalho e, enquanto tal, constitui-se num investimento social ou individual igual ou superior ao capital físico" (Frigotto, 1986, p. 136). E ao conferir qualidade ao trabalho, a educação também se constitui num mecanismo de redução da desigualdade econômica e social, pois propicia o aumento da produtividade da força de trabalho, resultando em melhores condições de vida para o indivíduo, para suas famílias e, naturalmente, no bem-estar geral da sociedade. Nela é atribuído valor econômico e social à educação.

A 'teoria do capital humano', no decorrer da expansão capitalista, sofreu vários ajustes conforme conjuntura econômica e política (Frigotto, 1986; 1998; 2000. Gentili 1998; 2002). No Brasil, sua penetração mais efetiva foi na década de 1970, compondo as bases ideológicas do 'desenvolvimentismo' calcado num modelo de desenvolvimento amplamente concentrador e associado ao capital internacional. E serviu para justificar e legitimar políticas do Estado (ditadura militar), na medida em que estas estariam situadas na idéia de democratização das oportunidades educacionais como 
forma de distribuição de renda e de desenvolvimento social - vivia-se a era do 'pleno emprego' e do 'milagre econômico'. Nos anos 80 e 90, a 'teoria do capital humano' sofre ajustes em decorrência da mudança do regime de acumulação do capital - globalização - e da inserção do novo padrão tecnológico de produção e de organização do trabalho - reestruturação produtiva. Conforme discorre Gentili (1998), houve o deslocamento da, em tese, função econômica integradora atribuída à escola para a função econômica de inserção, assumindo a tarefa de 'educar para o desemprego'.

\section{Da integração à inserção}

No contexto da 'ideologia desenvolvimentista', a educação, enquanto 'capital humano', era compreendida como um instrumento de modernização e competitividade, pois podia promover a modernização dos fatores de produção, especialmente pela qualificação da mão-de-obra, e um instrumento de equalização entre países e regiões, bem como entre classes; um recurso básico de mobilidade e equalização social e de justiça social.

Entendia-se que a passagem do estágio de 'subdesenvolvido' ao 'desenvolvido' era uma questão de tempo e de adequação de fatores, pois o progresso técnico, além de gerar emprego, exigia uma qualificação cada vez mais específica e permanente por parte do trabalhador, isto é, exigia que o trabalhador investisse naquilo de que era proprietário, o 'capital humano' (Frigotto, 1986), constituindo garantia de ascensão a um trabalho qualificado e, conseqüentemente, garantia de níveis de renda cada vez mais elevados.

Nessa perspectiva, desenvolveu-se a crença de que a 'desigualdade social', seja ela entre classes, países e regiões, não era uma questão orgânica do sistema capitalista em seu conjunto, isto é, não era vista como uma questão estrutural, mas algo conjuntural que podia ser corrigido mediante a alteração de fatores tais como a qualificação de trabalhadores e modernização da produção. Com isso, “a questão da desigualdade foi reduzida para uma questão de não-qualificação" (Frigotto, 1986, p. 136), recaindo toda a responsabilidade para o trabalhador e para o desempenho da escola.

No período 1980-1990, época de implementação das políticas neoliberais, de acomodação das polaridades ideológicas e de intensificação do avanço tecnológico, os argumentos passam a residir no aumento da competitividade como condição de inserção no mercado, agora, 'livre' e mundializado. No Brasil e em outros países latino-americanos de 'capitalismo dependente', a abertura dos mercados foi condicionada à renegociação da dívida externa e aos princípios e regras estipulados no Consenso de Washington, inserindo mudanças significativas (e 'modernizadoras') nas 
bases institucional, política e econômica. No âmbito da educação, a 'nova ordem mundial' impulsionada pelo Banco Mundial foi a de ampliar o nível de escolaridade da população, constituindo-se em melhoria da qualificação do trabalhador como condição de 'inserção no mercado de trabalho'.

Gentili (1998) disserta que, com o desmoronamento das condições econômicas e políticas que sustentavam as argumentações tecnocráticas e desenvolvimentistas da 'teoria do capital humano' dos anos 60 e 70, processa-se uma alteração em seu 'corpus teórico', que conduziu a "uma radicalização das premissas individualistas e meritocráticas que sustentam a teoria (...) e à perda definitiva do seu substrato liberal-democrático" (Gentili, 1998, p. 48). Essa alteração na 'teoria do capital humano' promoveu o deslocamento da, em tese, 'função econômica integradora' atribuída à escola, enfatizada no contexto do 'pleno emprego' ou do 'desenvolvimentismo', para a 'função econômica de inserção', no contexto da mundialização.

Na concepção de educação com 'função econômica integradora': "A escola e as políticas educacionais podiam e deviam ser um mecanismo de integração dos indivíduos à vida produtiva" (Gentili, 1998, p. 53). E a ênfase que era dada à função econômica da escola não era dissociada das demais funções integradoras: civil, política, social e cultural. Estabelecia-se um vínculo "quase linear nas possibilidades integradoras do aparato escolar", de forma a conceber que o bom desempenho da escola, em sua função de integrar os indivíduos à vida produtiva, era um requisito fundamental para o desempenho eficiente das funções de integração cultural, política e social promovidas pelo sistema educacional (Gentili, 1998, p. 53). A não eficácia do desempenho na 'função de integração econômica' poderia comprometer o desenvolvimento efetivo dos indivíduos e das nações, isto é, poderia impedir o pleno desenvolvimento das capacidades produtivas, o crescimento econômico, o desenvolvimento social do país e, conseqüentemente, a melhoria do bem-estar dos indivíduos.

No contexto da ideologia da globalização, esse vínculo entre o 'capital humano individual' e o 'capital humano social' foi rompido. A escola continuou sendo vista como um importante investimento para o desenvolvimento do 'capital humano individual', mas, como potencial de inserção no mercado. Um mercado mais competitivo e restrito, que exigia a "posse de um conjunto de saberes, competências e credenciais que o habilitam para a competição pelos empregos disponíveis" (Gentili, 1998, p. 53). Nessa perspectiva, expõe o autor: “(...) a educação não é, em tal sentido, um investimento em capital humano social. As economias podem crescer e conviver com uma elevada taxa de desemprego e com imensos setores da população fora dos benefícios do crescimento econômico" (Gentili, 1998, p. 53-54). 
Conforme explica Gentili (1998), a promessa integradora da escola foi 'desintegrada' e substituída por uma outra promessa, "de caráter estritamente privado: a promessa da empregabilidade" (Gentili, 1998, p. 51).

Sem negar a contribuição econômica da escolaridade, a concepção de educação no contexto da ideologia da globalização passou de uma 'lógica da integração', relacionada às necessidades e demandas de caráter coletivo (a economia nacional, a competitividade das empresas, a riqueza social etc.) para uma 'lógica econômica estritamente privada'. A ênfase está na capacidade e na competência que cada indivíduo deve adquirir no mercado educacional para atingir melhores condições de disputa e melhor posição no mercado de trabalho. Isto é:

Morta definitivamente a promessa do pleno emprego, restará ao indivíduo (e não ao Estado, às instâncias de planejamento ou às empresas) definir suas próprias opções, suas próprias escolas que permitam (ou não) conquistar uma posição mais competitiva no mercado de trabalho (Gentili, 1998, p. 51).

Para Gentili: "A garantia do emprego como direito social (...) desmanchou-se diante da nova promessa de empregabilidade como capacidade individual para disputar as limitadas possibilidades de inserção que o mercado oferece" (Gentili, 1998, p. 89). E observa: "Educar para o emprego levou ao reconhecimento (trágico para alguns, natural para outros) de que se devia formar também para o desemprego, numa lógica de desenvolvimento que transformava a dupla 'trabalho/ausência de trabalho' num matrimônio inseparável" (Gentili, 1998, p. 89).

Posto dissociado do direito à educação, o termo 'empregabilidade' articulou e deu coerência a um conjunto de orientações técnicas do quadro de especialistas do Banco Mundial, que foi apresentado como fundamental na superação da crise do desemprego dos anos 80 e 905, e que resultou em ações efetivas no campo da educação.

Frigotto (2000) vai identificar essas ações como "rejuvenescimento" da "teoria do capital humano", cujo conjunto de idéias envolto em uma nova casca de "conceitos" renovados reforçou a disseminação de ideologias como "fim do trabalho", "perda da centralidade do trabalho como categoria sociológica fundamental para entender a vida social", "o fim da sociedade do trabalho" ou o "fim da história" (Frigotto, 2000, p. 142), e construiu um novo senso comum sobre trabalho, educação e "sobre a própria individualidade" (Gentili, 1998, p. 52).

No entanto, logo nos primeiros anos de implementação da 'doutrina' neoliberal os dados da realidade iriam denunciar o caráter ideológico do conjunto de orientações técnicas do Banco Mundial para o sistema educacional dos países de 'capitalismo dependente'6. Contrapondo a 'teoria do 
capital humano' e a tese da 'empregabilidade' constatou-se ainda na década de 1990 que ao mesmo tempo em que houve a expansão do acesso à educação, a pobreza de uma parcela significativa da classe trabalhadora intensificou, os índices de desemprego e de trabalho informal aumentaram e o 'índice de desenvolvimento humano' (IDH) manteve-se praticamente inalterado.

No Brasil, por exemplo, entre 1992 e 1999, período em que as políticas econômicas neoliberais foram efetivamente implementadas, os números indicavam que o acesso à educação foi ampliado e o nível de escolarização dos brasileiros foi elevado, mas, contrapondo a 'tese da empregabilidade', não refletiu no mundo do trabalho - encontravam-se desempregados ou 'desocupados' em maiores taxas os jovens e os trabalhadores com níveis de escolaridade mais elevados?.

O trabalhador brasileiro, de certa forma, fez o 'dever de casa' - investiu em seu capital humano -, mas a tese da 'empregabilidade' foi 'derrubada', assim como foi revelado que a globalização não trazia benefícios globais. A promessa de que a riqueza 'derramaria' pelos setores mais pobres do mundo não foi cumprida, conforme colocação do próprio Stiglitz (2003) ${ }^{8}$, ao contrário, a pobreza foi globalizada (Chossudovsky, 1999).

Em meados da década de 1990, os intelectuais orgânicos do capital chegaram à conclusão de que não basta 'educar para o desemprego', isto é, não basta atribuir à escola a função de atender as demandas do capital, qualificando e modernizando as forças produtivas para aumentar a capacidade competitiva; não basta atribuir à escola a função de atender a demanda do trabalhador de inserção no mercado de trabalho - é preciso 'educar para sobreviver'; é necessário atribuir outras funções à escola. E opera-se uma outra etapa de 'rejuvenescimento' da 'teoria do capital humano' introduzindo elementos da 'teoria do capital social' de Robert Putnam.

\section{Ideologia do capital social: educar para sobreviver}

Na virada do novo milênio, setores políticos e econômicos dominantes encontram um obstáculo para reproduzir com certa condição de legitimidade as políticas econômicas neoliberais de hipertrofia financeira - a intensificação do pauperismo.

A pobreza ganha o status de ameaça em nível mundial. E o mundo se apresenta como um mundo livre e aberto às possibilidades produtivas e à acumulação de riquezas, sustentado por uma miséria crescente e pela degradação do meio ambiente num ritmo acelerado e devastador.

O pauperismo passa a ser visto como "pivô de uma série de outros problemas que reforçam a interdependência de todos os países e de todos os 
seres humanos", tais como: a Aids, o movimento de intensificação das migrações, o crescimento demográfico, a degradação do meio ambiente (Mestrum, 2005, p. 248), e mais adiante como pivô do terrorismo. Após os atentados de 11 de setembro de 2001, a pobreza não só ameaça a estabilidade econômica dos países centrais como também a estabilidade política. Conforme adverte Fukuyama (2005), “a pobreza é um campo fértil para a procriação do terrorismo" (Fukuyama, 2005, p. 40).

Para a equipe do Banco Mundial, "as lições dos programas de ajuste da década de 1980", com a promessa que não foi cumprida, e o fim da Guerra Fria removeram "as vendas dos olhos dos países doadores (Estados Unidos e seus aliados), que eles próprios haviam colocado" para evitar investigações sobre os "fracassos de governança". Sem uma ameaça ideológica houve a possibilidade de as teorias econômicas, políticas e sociais impulsionarem o pensamento sobre desenvolvimento, ao "vincular as noções de crescimento econômico, distribuição e redução da pobreza" (Bird, 2004, p. 3-15).

Vários encontros foram realizados entre setores políticos e econômicos dominantes para discutirem sobre essa possível ameaça de ruptura e a necessidade de redefinir ações voltadas para administrar este risco. Do encontro da Cúpula Mundial sobre Desenvolvimento Social (Copenhague, 1995) ao encontro de Cúpula do Milênio da Organização das Nações Unidas, realizado em 2000, em Nova York, definiu-se um conjunto de políticas que foi denominado de Políticas de Desenvolvimento do Milênio (PDMs). Neste conjunto de políticas sociais, as bases ideológicas de orientação são renovadas com a idéia de gerar 'capital social' e a tese defendida é a de que as reformas econômicas devem definir também ajustes nas dimensões culturais e sociais, de forma a "incorporar a dimensão humana no processo econômico" [grifos nossos] (Nunes, 2005)9.

O obstáculo, nessa concepção, é uma questão cultural. Com isso, compreendem que para introduzir um modelo de desenvolvimento que possibilite gerar oportunidades para os pobres é preciso promover o 'desenvolvimento humano', e isso não pode ser tarefa somente de um mercado em bom funcionamento 10. Para o Banco Mundial, a sociedade (não só a local ou nacional, mas também a sociedade global) deve ajudar o pobre a superar os obstáculos que impedem sua participação no mercado de forma livre e eqüitativa e a promover o desenvolvimento social.

Nesse sentido, a sociedade civil, como um todo, deve, de forma solidária e civicamente consciente, estimular a participação dos pobres nos ativos sociais disponíveis na sociedade, necessários ao 'desenvolvimento humano', e capacitá-los ao ingresso no mercado, tornando-os produtivos.

Assim, à dimensão econômica devem ser agregadas as dimensões cultural e social e à estabilidade econômica deve-se somar a estabilidade 
política criando, dessa forma, condições favoráveis à manutenção das políticas neoliberais no novo milênio. Para superar os obstáculos políticos e culturais e 'combater' a pobreza no contexto da globalização, não basta investir em capital humano, mas fundamentalmente em capital social.

\section{Da inserção à conformação}

A expressão 'capital social' não é nova, mas ganha uma roupagem nova a partir da obra de Robert Putnam 11 . O pesquisador elabora sua definição de 'capital social' em complemento à concepção de James Coleman (1990), enumerando vários exemplos dos atributos do 'capital social', que englobam tanto variáveis 'estruturais' quanto 'atitudinais'. Não existe em sua obra uma definição exata do termo, mas indicadores fundados durante vinte anos de pesquisa, entre 1970 e 1989, acompanhando o processo de implantação da descentralização administrativa da Itália moderna e o desempenho institucional dos governos (vinte governos regionais na totalidade) das regiões norte e sul.

Com a questão 'Por que alguns governos democráticos têm bom desempenho e outros não?', Putnam estava empenhado em examinar o potencial da reforma institucional como estratégia para a mudança política e também as restrições que o contexto social impõe ao desempenho institucional. Seu objetivo era avaliar o impacto da descentralização na redução da desigualdade entre as regiões norte e sul. Tanto o seu estudo sobre o desempenho institucional dos governos regionais da Itália moderna como a metodologia empregada tornaram-se referências para outras pesquisas em outros países.

Como resultado positivo da estratégia de descentralização administrativa, Putnam (2002) apontou que a política italiana tornou-se menos polarizada ideologicamente e mais voltada para problemas práticos da população e que as instituições do governo tornaram-se mais tolerantes e próximas do povo.

Entretanto, o pesquisador constatou que em regiões menos desenvolvidas esta estratégia não alterou a qualidade do governo, mantendo comportamentos observáveis no período da centralização, tais como: corrupção, burocracia, clientelismo, impasses políticos, entre outros. Putnam faz referência à região sul da Itália que se apresenta mais 'atrasada'. Na concepção de relação política e social restritamente administrativa de Putnam (2002), a diferença entre as regiões sul e norte da Itália se deu porque, historicamente, o norte estabeleceu uma relação mais horizontal com o governo, por apresentar uma forte tendência à organização e à formação de forças sociais - formação de associações. No sul houve o predomínio de uma relação vertical, de dependência do governo central (Putnam, 2002, p. 191)12. 
Na concepção do pesquisador, o problema da diferença de desenvolvimento econômico e social em qualquer formação histórico-social pode ser superado pondo no centro da questão a 'cultura cívica', pois sociedades com elevados graus de consciência cívica, de solidariedade e de confiança entre seus membros e instituições atingem níveis de bem-estar social superiores 13 .

Esta idéia de renovar a 'cultura cívica' encontra respaldo na proposta de Giddens da 'terceira via', no sentido da necessidade de alterar o quadro de declínio cívico configurado no final de século, como resultado da predominância da cultura de caráter individualista, pragmática e produtivista, que estimula a competitividade, o consumismo, o utilitarismo. Para Giddens (2005), o grande desafio é a 'governação' da contradição entre a expansão do individualismo e o conservadorismo filosófico de valores como família e democracia. Segundo o autor:

Numa sociedade em que a tradição e o costume estão perdendo seu domínio, a única rota para o estabelecimento da autoridade é a via democrática. O novo individualismo não corrói inevitavelmente a autoridade, mas exige que ela seja remodelada de forma ativa ou participatória (Giddens, 2005, p. 76).

A questão que o autor coloca é: “como deveríamos viver após o declínio da tradição e do costume; como deveríamos recriar a solidariedade social e reagir a problemas ecológicos?" (Giddens, 2005, p. 76). Para tais desafios ele propõe um "programa modernizante de democratização", um mix de conservadorismo moral para remontar a solidariedade social corroída pelo individualismo exacerbado e de desenvolvimento de atitudes ecologicamente modernas para reconhecer o dualismo dos avanços tecnológicos. Segundo o autor, "um programa capaz de controlar adequadamente as forças que a globalização e a mudança tecnológica desencadearam" (Giddens, 2005, p. 79). Para tal, é preciso "combinar solidariedade social com uma economia dinâmica" [grifos nossos] (Giddens, 2001, p. 15).

Na mesma ocasião as idéias de Amartya Sen tornavam-se conhecidas. Sen (2001) defende a tese de que os pobres sofrem de 'privações múltiplas' e estas privações podem afetar o seu 'potencial de realização'. Para o autor, a pobreza não é só uma questão de renda, mas de liberdade de escolha e de oportunidade para deslanchar seus talentos e habilidades. Ela possui uma característica multidimensional. Em sua concepção, a pobreza é fonte potencial de desenvolvimento e a educação (formal e informal) é vista como mecanismo que oportuniza o pobre a deslanchar este potencial por propiciar competências requeridas pelo mercado.

As idéias de renovar a 'cultura cívica', estimulando o sentimento solidário e comunitário, principalmente nos grupos mais pobres, no sentido 
de serem solidários com aqueles que têm preocupações semelhantes para empreenderem juntos uma 'jornada pela vida', e de pobreza como 'fonte potencial de desenvolvimento' vão ao encontro dos ensejos dos setores dominantes, sinalizando a saída que buscavam para amenizar as tensões do final do século.

Com todos esses argumentos o Banco Mundial, o Banco Interamericano de Desenvolvimento (BID), a Comissão Econômica para a América Latina e Caribe (Cepal) e a Organização das Nações Unidas para a Educação, a Ciência e a Cultura (Unesco), cada um dentro de sua especificidade, passam a considerar o investimento em 'capital social' como condição essencial para que os países mais pobres e 'emergentes' tenham êxito no processo de abertura de seus mercados. 'Renovação cívica', 'solidariedade', 'confiança', potencial produtivo ou vocação produtiva dos pobres são as ideologias da ordem.

\section{Educar para o conformismo}

Para a equipe do BID, o 'capital social' é um elemento que facilita a 'inclusão social' de grupos 'marginalizados', o 'combate' à pobreza e à desigualdade social. A 'exclusão social' é definida pela equipe do BID (2004) como: “a incapacidade de um indivíduo de participar do funcionamento básico político, econômico e social da sociedade em que vive" ou "a negação do acesso igualitário a oportunidades impostas por alguns grupos da sociedade a outros" (BID, 2004, p. 5). Essa 'incapacidade' de participação, ou de ter "voz e poder na sociedade", é resultante de processos sociais e culturais, que "privaram socialmente" o indivíduo de realizar seus desejos e impor suas escolhas, e o condenaram à condição de pobreza durante gerações. Nessa perspectiva, a cultura, enquanto

valores que inspiran la estructura y comportamiento de una sociedad y de sus distintos miembros, (....) es un factor decisivo de cohesión social. En ella, las personas pueden reconecerse mutuamente, cultivarse, crecer en conjunto y desarrollar la autoestima colectiva (BID, 2001, p. 9).

Nesse sentido, destaca a equipe do BID (2004):

Para combater essa natureza permanente da exclusão, a proteção social e outras medidas de curto prazo desenvolvidas para ajudar os pobres a enfrentar eventos adversos devem ser complementadas por políticas mais abrangentes, que ampliem o acesso a oportunidades. A característica de transmissão da falta de oportunidade de uma geração a outra também destaca a importância da comunidade e 
da família na formulação de políticas destinadas a interromper essa transmissão (BID, 2004, p. 6).

O processo de globalização da economia, para o BID, que "recompensa o trabalho altamente qualificado em detrimento do trabalho pouco qualificado" (BID, 2004, p. 4), intensificou as desigualdades salariais na América Latina, tornando-as mais visíveis. E, com o fortalecimento da democracia, aumentou os processos participativos e as demandas sociais dos cidadãos: "Mulheres, povos indígenas, portadores de deficiência e, mais recentemente, grupos de afrodescendentes levantaram suas vozes no processo de formulação de políticas" (BID, 2004, p. 4). Explica que nesse contexto histórico, em que há a intensificação das desigualdades e o aumento de demandas sociais, os organismos multilaterais decidiram voltar-se para a questão da pobreza e da desigualdade. Assim, expressa o Banco Mundial:

(...)a percepção amplamente compartilhada de que os atuais paradigmas de desenvolvimento não são capazes de atender às preocupações sociais prementes e às desigualdades históricas, (...) organismos internacionais de desenvolvimento decidiram abraçar a meta de inclusão social e apoiar não apenas pesquisas sobre as causas da pobreza e da desigualdade, mas também as medidas necessárias para combatê-la (BID, 2004, p. 4).

Para a equipe do Banco Mundial a concepção de 'capital social' enfatiza as relações interinstitucionais com a comunidade, "refere-se às instituições ${ }^{14}$, relações e normas sociais que dão qualidade às relações interpessoais em uma dada sociedade. A coesão social é a argamassa que mantém as instituições em contato entre si e as vincula ao cidadão visando à produção do bem comum" (Bird, 2002, p. 10). E são as organizações da sociedade civil e o Estado que podem lançar os alicerces institucionais para que haja cooperação entre os grupos visando ao bem comum. Segundo o Banco: "Uma visão integradora do capital social reconhece que as micro, meso e macro- instituições coexistem e podem se complementar entre si" (Bird, 2000a, p. 133).

Os cepalinos acreditam que na medida em que aumenta o 'capital social' de uma pessoa, aumenta o seu interesse pelos demais membros, isto é, aumenta o sentimento de solidariedade e, com isso, ampliam-se as oportunidades de adquirir benefícios econômicos e bens socioemocionais já disponíveis na sociedade. Conforme observa Robison, Siles e Schmid:

Los esfuerzos de reducción de la pobreza ejercen una influencia positiva en el capital social de un país, porque disminuyen la segregación. Además, las iniciativas de inversión en capital social, que conectan a personas anteriormente 
desvinculadas, tienden a aminorar la desigualdad de ingresos y la pobreza que contribuyen a esa segregación (Robison; Siles; Schmid, 2003, p. 55).

Esse 'novo paradigma' visa a superar a pobreza através da colaboração e da cooperação dos cidadãos no processo de alargamento do acesso dos mais pobres aos benefícios econômicos e bens socioemocionais já disponíveis na sociedade. Nesta perspectiva, o papel 'ativo' da sociedade civil, da comunidade e dos grupos é fundamental, pois a ampliação deste 'recurso social' (o 'capital social' ou confiança, cooperação, reciprocidade) requer mudanças culturais. Esse modelo idealizado de 'sociedade solidária' que evita o conflito, educa para a tolerância e para a confiança mútua, coloca Fukuyama (2005), exige certos "hábitos mentais" (Fukuyama, 2005, p. 9).

Assim, na perspectiva da 'teoria do capital social' a educação passa a exercer a dupla função de aprimorar o capital humano para aumentar a competitividade e a produtividade do indivíduo e de construir uma 'cultura cívica' como mecanismo de construção de uma sociedade solidária, harmônica, confiável, 'da paz'15, necessário para aliviar a pobreza. Alarga-se o papel da educação e restringe sua função polítical6.

Diferente das políticas anteriores que operavam a descentralização no plano organizacional e gerencial fundadas na tese do 'Estado mínimo', o Estado passa a ser enfatizado como uma esfera central na condução de políticas sociais, mas em sua dimensão 'educadora', pois os gastos do aparelho estatal nas esferas sociais devem manter-se reduzidos.

$\mathrm{O}$ argumento anterior que sustentou a contra-reforma dos anos 90 retirando o Estado do controle econômico, de esferas estratégicas da produção e da comercialização, além da 'desresponsabilização' do Estado em relação às expressões da 'questão social' - foi a ineficácia estatal de caráter burocrático e corruptível - de 'agente de desenvolvimento' passou a ser visto como um 'obstáculo'. Agora, clama-se o retorno do Estado como agente de desenvolvimento, intervindo na esfera econômica, mas na forma de conduzir os mecanismos que garantam a estabilidade politica e construam um mercado forte.

Para Fukuyama (2005), o fracasso da reforma econômica liberalizante nos países dependentes não foi por causa das medidas do Consenso de Washington, mas por causa das fracas bases institucionais desses países. Segundo ele, a ênfase na redução da atividade estatal foi compreendida como corte generalizado na capacidade do Estado. Os Estados deveriam ser reduzidos em determinadas áreas, mas em outras áreas sua presença deveria ser fortalecida, e isso não ocorreu. No processo de redução do escopo do Estado, muitos países reduziram a sua força, enquanto que o caminho ideal para reforma teria sido reduzir o escopo e aumentar a força. Os países 
tomadores de empréstimos não compreenderam corretamente as medidas impostas pelo FMI. Conforme observa o autor: "O problema está na incapacidade conceitual básica de decifrar as diferentes dimensões de estaticidade e compreender como tais dimensões se relacionam com o desenvolvimento econômico" (Fukuyama, 2005, p. 20).

Como expressão desse consenso entre as principais agências multilaterais, as medidas anunciadas e objetivadas pelas PDMs visam a: promover mudanças institucionais baseadas na 'boa governança', isto é, na formação de um ambiente de cooperação entre Estado-mercado-sociedade civil em vários níveis, local, nacional, regional e global, de forma a instaurar um ambiente de estabilidade econômica e, principalmente, política; construir uma 'cultura cívica' pautada em valores de solidariedade e de cooperação, e que venha a fortalecer os laços de confiança entre indivíduos e instituições como forma de construir o bem-estar social; operar um tipo de desenvolvimento que não se restrinja ao âmbito econômico, mas que inclua noções de responsabilidade social e ambiental, compreendido como desenvolvimento sustentável, já que o padrão de desenvolvimento, de produção e de consumo dos países centrais não pode mais ser reproduzido nos países ditos 'emergentes' sem implicações ambientais.

A idéia de desenvolvimento sustentável não enfatiza mais as questões estritamente ambientais como foi difundida nos anos 80. A idéia que foi sendo configurada em torno da concepção de desenvolvimento sustentável para o novo milênio enfatiza o desperdício de potenciais produtivos não só material, mas também o desperdício de recursos humanos - representados pela massa de trabalhadores excluídos do processo produtivo; de recursos materiais - as matérias-primas consumidas de forma avassaladora; de recursos naturais - principalmente aqueles que produzem energia. No entanto, a preocupação não gira em torno somente do desperdício de recursos em si, mas também da possibilidade de se gerar conflito social por causa dele. Nessa perspectiva, o que está em foco não é somente estabelecer estratégias de desenvolvimento econômico, mas, sobretudo, de desenvolvimento social para amenizar os riscos e as seqüelas advindas de uma economia liberada. Conforme expressa a equipe do Banco Mundial: “a exclusão de grandes segmentos da sociedade desperdiça recursos potencialmente produtivos e gera conflito social" (Bird, 2004, p. 5).

As tarefas que estão postas para os países de 'capitalismo dependente' e suas instituições e organizações são: criar esforços conjuntos para superar os infortúnios causados pelo aumento da pobreza, da desigualdade e do desemprego; identificar o problema e a possível superação, baseado na 'vocação produtiva' de cada grupo, comunidade ou zona de pobreza localizada; promover a oportunidade de cada um desenvolver suas capacidades produtivas em atividades econômicas alternativas que propiciem 
sustentabilidade econômica ou aliviar o problema com políticas de ação afirmativa e compensatória; elevar não só no âmbito da renda, mas reciprocamente no âmbito 'cultural' as camadas mais pobres, instituindo competências emocionais e morais - principalmente naqueles que já não se enquadram nas condições específicas do trabalho no novo padrão tecnológico de produção -, desenvolvendo o espírito de iniciativa e o cultivo do 'capital social' como meio de gerar renovação econômica - educar para a sobrevivência.

Assim, para a parte da classe trabalhadora que ainda dispõe de potencial competitivo no mercado de trabalho mantêm-se as ideologias do capital humano e da empregabilidade; os trabalhadores que perderam a condição de vender sua força de trabalho e que se encontram miseráveis, embrutecidos, degradados moralmente vão 'vegetar' na base da caridade público-privada; para a camada da classe trabalhadora que amarga a redução da demanda de sua força de trabalho, que se encontra empobrecida e em condição de precariedade moral, mas que ainda possui condição produtiva, recomendase investir em 'capital social'.

Enfim, a saída encontrada pelos intelectuais orgânicos do capital é: construir uma sociedade solidária e harmoniosa com um 'Estado inteligente' e 'ativo' - 'eficiente e competente' nas tarefas de impulsionar um modelo de desenvolvimento em harmonia com o mercado e as organizações da sociedade civil, administrar os riscos e aliviar a condição de pobreza (não só com programas de renda mínima, mas também desenvolvendo a capacidade produtiva dos pobres) ${ }^{17}$. Operam-se, assim, mecanismos de despolitização e conformação com as condições impostas pelo grande capital, indo para além de educar para a sobrevivência, educando para a conformação.

Tem-se na abordagem do 'capital social' como mecanismo de redução da desigualdade e de alívio da pobreza, entre outras questões, duas que nos remetem às categorias centrais em Gramsci: Estado-educador e sociedade civil.

O Estado burguês é, na concepção de Gramsci (2000b), um Estado educador:

A classe burguesa põe-se a si mesma como um organismo em contínuo movimento, capaz de absorver toda a sociedade, assimilando-a a seu nível cultural e econômico; toda a função do Estado é transformada: o Estado torna-se 'educador'... [grifos nossos] (Gramsci, 2000b, p. 271).

Gramsci afirma que "o Estado deve ser concebido como 'educador' na medida em que tende precisamente a criar um novo tipo ou nível de civilização" (Gramsci, 2000b, p. 28), exercendo a função educadora, que é a de dirigir e organizar a sociedade para uma determinada vontade política. 
E a categoria sociedade civil em Gramsci é compreendida como espaço do Estado (ampliado) “dedicado a promover a articulação e a unificação de interesses, a politizar ações e consciências e a superar tendências corporativas ou concorrenciais" (Nogueira, 2003, p. 223), com fins de construção de projetos globais de sociedade e de articulação ético-política. A sociedade civil é essencialmente o espaço da política (em seu sentido amplo), de disputa de poder e da dominação (direção política, intelectual e moral).

O Estado burguês, enquanto Estado-educador, no decorrer de seu processo histórico e impulsionado pela sua própria essência contraditória, expandiu sua esfera de domínio desenvolvendo capacidades estratégicas, cada vez mais refinadas, de impor a adesão à sua forma particular de ver o mundo. E esta função educadora pode ser identificada ao longo do processo de desenvolvimento histórico do modo de produção capitalista - seja para civilizar e disciplinar aquela massa de trabalhadores 'livres' ainda em formação, libertando-os das tradições acríticas do Ancien Règime e formando-os pelos valores da laboriosidade burguesa, seja como estratégia de segurança internacional para conter o avanço do comunismols, seja para modernizar e aumentar a produtividade ('teoria do capital humano').

A outra problemática posta na abordagem do 'capital social' é o processo de despolitização e enfraquecimento dos embates no interior da sociedade civil, com sua idéia de construir uma sociedade solidária e coesa, sem conflitos de interesses e confrontos como mecanismo de 'combate' as mazelas sociais. Justamente essa categoria de Gramsci, “um conceito, complexo e sofisticado, com o qual se pode entender a realidade contemporânea (...) um projeto politico, abrangente e igualmente sofisticado, com o qual se pode transformar a realidade", que vem sendo expandida sob outras óticas pretensamente "desinteressadas" (Nogueira, 2003, p. 219).

O que se observa é que no atual estágio do capitalismo, o Estado liberal-democrático ${ }^{19}$ busca permanentemente aprimorar seus mecanismos de hegemonia ao exercer as funções de 'administrador dos ciclos de crise' do capital e de Estado-educador, em harmonia com o mercado e com a 'sociedade civil'. Um tipo de sociedade civil convertido num mítico 'terceiro setor', como sustentou Coutinho (2006), que vai exercer também a função educadora através de seus 'aparelhos privados de hegemonia', atuando diretamente nas esferas microssociais, visando a uma 'reforma intelectual e moral' para o enfrentamento da 'questão social' (Coutinho, 2006; Montaño, 2002).

Nesse sentido, entende-se que a ideologia do capital humano rejuvenescida com elementos da ideologia do capital social não vai tratar somente de 'educar para a sobrevivência', mas 'educar para o conformismo'. Amplia-se o caráter economicista ou produtivista da educação, inserindo-se 
elementos pretensamente humanizantes, éticos e moralmente voltados para a conformação da vontade.

\section{Conclusão}

Ao longo de várias décadas de disseminação da ideologia do capital humano, o que se constatou foi que, ao invés de equalização social, como difundira, operou-se a intensificação da concentração de renda e a desigualdade ficou mais acentuada. Contrapondo a ideologia da empregabilidade, ampliou-se o exército de reserva agora com trabalhadores mais qualificados e criou-se um outro tipo de exército, não de reserva, mas de trabalhadores que jamais serão 'inseridos' ou 'incluídos' ou 'integrados' no mercado formal, que vão depender da 'caridade público-privada'.

Já logo nos primeiros anos de implementação das políticas econômicas neoliberais identificou-se que seu fracasso seria em breve, mas que, contudo, ideológica e culturalmente havia triunfado. No entanto, em meados da década de 1990, suas bases ideológicas foram confrontadas com os dados da realidade e com os movimentos anti-globalizantes. Constatou-se que as economias não podiam crescer convivendo "com elevadas taxas de desemprego e com imensos setores da população fora dos benefícios do crescimento econômico", como apontou Gentili (2002, p. 54) - a estabilidade política era necessária.

O risco de ruptura da coesão social e a pobreza assombram os setores dominantes. Assim, buscam cimentar no senso comum que diante do inevitável domínio do mercado globalizado é necessário que se construa política e culturalmente uma sociedade coesa e harmônica, com um Estado moderno, ativo e inteligente, de forma a amenizar as conseqüências e administrar os riscos impostos pelas intempéries do mercado.

Rapidamente, o coletivo dos intelectuais orgânicos do capital elaborou novas bases ideológicas para criar as condições necessárias à reprodução do capitalismo na virada do século. Essas novas bases ideológicas reforçam com mais intensidade o processo de despolitização, comparadas às ideologias disseminadas no início de implementação das políticas neoliberais, porque não incorporam o otimismo disseminado no período 1970-1990 em relação às infindáveis possibilidades produtivas do mundo globalizado.

No âmbito da educação, mantém-se a função econômica de inserção, entretanto acrescida de uma outra tarefa, a de gerar capital social. A 'lógica econômica estritamente privada' é mantida, não como instrumento de equalização entre classes, países e regiões, conforme foi difundido no contexto da ideologia do desenvolvimento, mas como potencializador de 
igualdades de oportunidades entre indivíduos e como mecanismo de contenção de conflitos e de desperdício de potenciais produtivos - material e humano (este último representado pela massa de trabalhadores excluídos do processo produtivo e, conseqüentemente, do consumo).

Nesta perspectiva, conclui-se que os conteúdos expressos nas 'políticas de desenvolvimento do milênio' são despolitizadores e conformadores, pois não só encobrem o caráter contraditório do movimento do capital e, com isso, o caráter conflitivo que insere as relações sociais na sociedade capitalista, como também procuram naturalizar o atual contexto políticoeconômico e cimentar no senso comum da classe trabalhadora que não há outra saída senão reunir esforços para sobreviver. Instaura-se um processo de desconstrução das possibilidades de luta e de correlação de forças que, na concepção de Gramsci, insere a dinâmica da sociedade civil.

$\mathrm{O}$ avanço desta perspectiva pode trazer implicações perversas ao sistema educacional brasileiro, tendo em vista a especificidade da formação histórico-social do país e sua condição na divisão internacional do trabalho. Uma concepção de educação ('periférica') como mecanismo de 'redução da pobreza' pode gerar implicações no próprio ethos acadêmico dos sistemas educacionais, em seus vários níveis e segmentos e, especificamente, na educação básica, que atende mais de $88 \%$ da população escolar, reforçando a tendência de 'apartheid educacional'.

Nesse sentido, torna-se fundamental ter clareza que o avanço desta perspectiva está condicionado ao movimento das correlações de forças externas e internas e o seu retrocesso demanda um processo contra-hegemônico por parte das forças sociais comprometidas com a transformação social e a construção de um projeto societário nacional-popular. É fundamental a defesa intransigente do sentido gramsciano de sociedade civil, como um terreno de lutas e conflitos, superando as noções genéricas que associam a sociedade civil ao terreno da solidariedade e da harmonia, e esvaziam seu caráter estatal e público. É preciso "libertar-se das ideologias parciais e falazes" (Gramsci, 1999, p. 134), porque também se trata de 'batalha das idéias', e afirmar a luta pela democratização dentro dos princípios de igualdade, solidariedade e democracia voltados para a emancipação humana. 


\section{Notas}

1 Bolsista recém-doutora pela Fundação Carlos Chagas Filho de Amparo à Pesquisa do Estado do Rio de Janeiro (Faperj) no Programa de Pós-graduação de Políticas Públicas e Formação Humana da Universidade do Estado do Rio de Janeiro (PPFH/ UERJ). Doutora em Serviço Social pela Universidade Federal do Rio de Janeiro (UFRJ). $<$ vaniacmotta@gmail.com>

Correspondência: Rua São Francisco Xavier, 524, Pavilhão João Lyra Filho, $12^{\circ}$ andar, bloco F, sala 12.111, Maracanã, Rio de Janeiro, RJ, CEP 20550-013.

2 Este artigo integra parte da tese de doutorado Da ideologia do capital humano à ideologia do capital social: as políticas de desenvolvimento do milênio e os novos mecanismos hegemônicos de educar para o conformismo, defendida no Programa de Pós-graduação em Serviço Social da Universidade Federal do Rio de Janeiro, Rio de Janeiro, 2007.

3 Gramsci (2000b) apresenta a categoria 'conformismo social', tratada no Caderno 13, parágrafo 7: “Questão do 'homem coletivo' ou do 'conformismo social': Tarefa educativa e formativa do Estado, cujo fim é sempre o de criar novos e mais elevados tipos de civilização, de adequar a 'civilização' [grifos nossos] e a moralidade das mais amplas massas populares às necessidades do contínuo desenvolvimento do aparelho econômico de produção e, portanto, de elaborar também fisicamente tipos novos de humanidade" (Gramsci, 2000b, p. 23).

4 Ideologia para Gramsci é "toda concepção particular dos grupos internos da classe que se propõem ajudar a resolver problemas imediatos e restritos" (Gramsci, 1999, p. 140). Mas sua concepção de ideologia também traz elementos combativos, uma vez que ele compreende que "as crenças populares têm a validade das forças materiais" (Gramsci, 1999, p. 26), com isso, ideologias para o autor "são fatos reais que devem ser combatidos e revelados em sua natureza de instrumentos de domínio" (Gramsci, 1999, p. 193).

5 Pregava-se a necessidade de dinamizar o mercado, através da redução dos encargos patronais, da flexibilização trabalhista e da formação profissional permanente (Leher, 1998).

${ }^{6}$ A expressão entre aspas indica que se trata da categoria elaborada por Florestan Fernandes.

7 Fontes: Organização Internacional do Trabalho (OIT). Oficina Regional América Latina e Caribe. Panorama Laborial: evolucion del desempleo juvenil 1999, 2000, 2001; Ipea. Políticas Sociais - Acompanhamento e Análise. Anexo Estatístico, n 5, ago. 2002; IBGE. Síntese de Indicadores Sociais, 2004. Ver Motta (2007).

8 Joseph Stiglitz (2003) atuou no Banco Mundial no período entre 1997-2000 como economista-chefe e como vice-presidente sênior entre 2000-2005. Foi um dos críticos da 'metodologia imperialista' aplicada pelo FMI na condução da abertura dos mercados dos países 'em desenvolvimento'.

9 Para Tarson Nunes, historiador e especialista em sociologia, da Usina Instituto de Políticas Públicas de Gestão Local, Porto Alegre, RS, o desenvolvimento do 'capital social' permite introduzir essa dimensão mais humanizada nas políticas econômicas. Uma opção que vem crescendo, tornar o capitalismo menos selvagem. Como se fosse possível 
introduzir uma dimensão mais humana na lógica do capitalismo, que prioriza o capital na relação de produção; onde as atividades e produtos humanos se convertem em mercadoria, não para satisfazer as necessidades mais elementares da população, mas para criar necessidades ampliadas de consumo. A lógica que permeia este modo de produção da existência é o incessante e insaciável movimento de valorização do capital, de ganho operado pelos capitalistas; tudo vira mercadoria; tudo é vendável. Como colocou Polanyi (2000), a economia capitalista, mais do que uma economia de mercado, é uma economia para o mercado. Marx esclareceu que o capitalismo só pode existir em expansão contínua, impulsionado pela competição, pelo lucro sempre ampliado; num processo de mercantilização crescente de todas as atividades e produtos humanos. Neste processo, condiciona com suas regras as várias esferas da vida social; com a superexploração do trabalho. A contradição essencial desse modo de produção é que, nas palavras de Marx: "Nas mesmas condições em que se produz a riqueza, produz-se também a miséria" (Marx, 2002, p. 749).

10 Para o Banco Mundial (Bird, 2004), os países de capitalismo dependente devem tornar os mercados mais favoráveis aos pobres; os mercados são importantes para os pobres porque geram crescimento e expandem oportunidades. "E é por isso que os doadores internacionais e governos de países em desenvolvimento, em especial os democraticamente eleitos, têm promovido reformas que favorecem o mercado" (Bird, 2004, p. 60).

11 Robert Putnam é americano, professor da Universidade de Harvard. Sua pesquisa sobre o desempenho institucional dos governos regionais da Itália moderna foi publicada nos Estados Unidos em 1993, pela Princeton University Press, com o título: Marking democracy work: civic traditions in modern Italy, e no Brasil foi publicada pela editora da Fundação Getulio Vargas, em 1996, com o título Comunidade e democracia: a experiência da Itália moderna (em 2002, estava na terceira edição).

12 É possível fazer uma crítica dessa análise de Putnam a partir de Gramsci, mais especificamente em suas reflexões sobre 'a questão meridional'. Putnam não considerou em sua análise as 'relações de poder e de dominação estruturais e superestruturais' que permearam a formação social italiana e sua especificidade em relação à dinâmica do sistema capitalista global. Na perspectiva gramsciana, a conservação de resíduos feudais no sul é resultado do domínio dos latifundiários em aliança com a burguesia liberal, sobretudo, como fornecedor de mão-de-obra barata para a indústria do norte (Coutinho, 1999; Motta (2007).

13 Tese que ganhará reforço de Fukuyama (1995) em sua obra Confiança: valores sociais e criação de prosperidade e será totalmente incorporada e difundida pela equipe da Cepal, no final dos anos 90 .

14 “(...) por instituições sociais entendem-se os sistemas de parentescos, as organizações locais e as redes dos pobres"' (Bird, 2000a, p. 134).

15 A expressão 'cultura da paz' faz parte de um dos programas da Unesco (2005).

16 Embora na especificidade do debate sobre a profissionalização docente, Shiroma e Evangelista (2004) constroem a expressão alargamento-restrição para apontar que nas últimas décadas têm sido alargadas as atribuições do professor, acrescidas com a tarefa de administrar a 'crise' da escola, ao mesmo tempo em que ocorre a restrição da dimensão política inerente à ação pedagógica. Entende-se que se trata de uma categoria que pode ser aplicada em outras temáticas sobre políticas da educação. 
17 São inúmeros os programas e projetos governamentais e não-governamentais que atuam no diagnóstico e desenvolvimento da vocação produtiva de comunidades rurais e periféricas.

18 Gestão de McNamara no Banco Mundial, entre 1971-1980 (Leher, 1998).

19 Coutinho (2000) explica que quando a sociedade civil se torna relativamente autônoma, 'ocidentalizada', quando já não é mais possível o Estado impor de modo coercitivo sua ideologia, pode dizer que "a sociedade passou de seu período meramente liberal para um período liberal-democrático" (Coutinho, 2000, p. 18).

\section{Referências}

BID. Banco Interamericano de Desenvolvimento. Reducción de la pobreza y fortalecimeinto del capital social y la participación: La acción reciente del Banco Interamericano de Desarrollo, Santiago do Chile, 20 set. 2001.

Los objectivos de desarrollo del milenio en América Latina y el Caribe: retos, acciones y compromisos. Banco Interamericano de Desarrollo, Washington, DC, jan. 2004.

BIRD. Banco Mundial. Luta contra a pobreza: relatório sobre o desenvolvimento mundial 2000/2001. Banco Mundial, Washington, DC, set. 2000a.

Do confronto à colaboração: relações entre a sociedade civil, o governo e o Banco Mundial no Brasil. Brasília, DF: Banco Mundial, jun. 2000b.

Relatório de progresso da estratégia de assistência ao país para a República Federativa do Brasil. Washington, DC: Banco Mundial, maio 2002.

Desenvolvimento e redução da pobreza: reflexão e perspectiva. Preparado para as reuniões anuais de 2004 do Banco Mundial e do Fundo Monetário Internacional). Washington, DC: Communications Development Incorporated, out. 2004.
CHOSSUDOVSKY, Michel. A globalização da pobreza: impactos das reformas do FMI e do Banco Mundial. São Paulo: Moderna, 1999.

COLEMAN, James S. Foundations of social theory. Londres; Cambridge: Havard University Press, 1990.

COUTINHO, Carlos Nelson. Gramsci: um estudo sobre seu pensamento político. Rio de Janeiro: Civilização Brasileira, 1999.

Intervenções: o marxismo na batalha das idéias. São Paulo: Cortez, 2006.

- Cultura e sociedade no Brasil: ensaios sobre idéias e formas. 2. ed. rev. e ampl. Rio de Janeiro: DP\&A, 2000.

FRIGOTTO, Gaudêncio. A produtividade da escola improdutiva. 2. ed. São Paulo: Cortez; Autores Associados, 1986 (Coleção Educação Contemporânea).

(Org.) Educação e crise do trabalho: perspectivas de final de século. 2. ed. Petrópolis: Vozes, 1998.

Educação e a crise do capitalismo real. 4. ed. São Paulo: Cortez, 2000.

FUKUYAMA, Francis. Confiança: valores sociais e criação de prosperidade. Lisboa: Gradiva, 1995. 
Construção de Estados: governo e organização no século XXI. Rio de Janeiro: Rocco, 2005.

GENTILI, Pablo. Educar para o desemprego: a desintegração da promessa integradora. In: FRIGOTTO, Gaudêncio. (Org.). Educação e crise do trabalho: perspectivas de final de século. 2. ed. Petrópolis: Vozes, 1998.

Três teses sobre a relação trabalho e educação nos tempos neoliberais. In: LOMBARDI, José C.; SAVIANI, Dermeval.; SANFELICE, José Luiz. (Orgs). Capitalismo, trabalho e educação. Campinas: Autores Associados, HISTEDBR, 2002 (Coleção educação contemporânea), p. 45-60.

GIDDENS, Anthony. A terceira via e seus críticos. Rio de Janeiro: Record, 2001.

A terceira via: reflexões sobre o impasse político atual e o futuro da socialdemocracia. 5. ed. Rio de Janeiro: Record, 2005.

GRAMSCI, Antonio. Cadernos do cárcere, volume 1: Introdução ao estudo da filosofia. A filosofia de Benedetto Croce. Edição e tradução Carlos Nelson Coutinho. Colaboração de Luiz Sérgio Henriques e Marco Aurélio Nogueira. Rio de Janeiro: Civilização Brasileira, 1999.

Cadernos do cárcere, volume 2: Os intelectuais. O princípio educativo. Jornalismo. Edição e tradução Carlos Nelson Coutinho. Colaboração de Luiz Sérgio Henriques e Marco Aurélio Nogueira. Rio de Janeiro/RJ: Civilização Brasileira, 2000a.

Cadernos do cárcere, volume 3: Maquiavel. Notas sobre o Estado e a política. Edição e tradução Carlos Nelson Coutinho. Colaboração de Luiz Sérgio Henriques e Marco Aurélio Nogueira. Rio de Janeiro: Civilização Brasileira, 2000b.

LEHER, Roberto. Da ideologia do desenvolvimento à ideologia da globalização: a educação como estratégia do Banco Mundial para o 'alívio da pobreza'. Tese de doutora- do defendida no Programa de Pós-graduação em Educação da Universidade de São Paulo, São Paulo, 1998.

MARX, Karl. O capital: crítica da economia política: livro I. 18. ed. Rio de Janeiro: Civilização Brasileira, v. 2., p. 749.

MESTRUM, Francine. A luta contra a pobreza: utilidade pública de um discurso na nova ordem mundial. In: AMIN, Samir; HOUTART, François (Orgs.). Mundialização das resistências: o estado das lutas. São Paulo: Cortez, 2003, p. 241-258.

MONTAÑO, Carlos. Terceiro setor e questão social: crítica ao padrão emergente de intervenção social. São Paulo: Cortez, 2002.

MOTTA, Vânia C. Da ideologia do capital humano à ideologia do capital social: as políticas de desenvolvimento do milênio e os novos mecanismos hegemônicos de educar para o conformismo. Tese de Doutorado defendida no Programa de Pós-graduação em Serviço Social da Universidade Federal do Rio de Janeiro, Rio de Janeiro, 2007.

Banco Mundial, pobreza e a ideologia do capital social. Ser Social, Revista do Programa de Pós-graduação em Política Social da UnB, Brasília, n.18, jan./jun. 2006. p. 303-333.

NOGUEIRA, Marco Aurélio. As três idéias de sociedade civil, o Estado e a politização. In: COUTINHO, Carlos Nelson; TEIXEIRA, Andréa de Paula. (Orgs.) Ler Gramsci, entender a realidade. Rio de Janeiro: Civilização Brasileira, 2003.

NUNES, Tarson. Historiador fala sobre o conceito que busca compreender as desigualdades sociais. Entrevista realizada por Laura Giannecchini, 31 jan. 2005. Disponível em: <www.setor3.com.br/senac>. Acesso em: 24 mar. 2005.

POLANYI, Karl. A grande transformação: as origens da nossa época. 2. ed., 11. reimp. Rio de Janeiro: Campus-Elsevier, 2000. 
PUTNAM, Robert. Comunidade e democracia: a experiência da Itália moderna. Rio de Janeiro: editora FGV, 2002.

ROBISON, Lindon J., SILES, Marcelo E.; SCHMID, Allan A. El capital social y la reducción de la pobreza: hacia in paradigma maduro. In: ATRIA, Raúl et al. (Comps.). Capital social y reducciòn de la pobreza en América Latina y el Caribe: en busca de un nuevo paradigma. Santiago do Chile: Comisión Económica para América Latina y el Caribe. University of Michigan Press, jan. 2003, livro n. 71, parte 2, Capital social y pobreza: el marco analítico, cap. 3, p. 51-113.

SCHWARTZMAN, Simon. Pobreza, exclusão social e modernidade: uma introdução ao mundo contemporâneo. São Paulo: Augurium, 2004.

SHIROMA, Eneida O.; EVANGELISTA, Olinda. A colonização da utopia nos discursos sobre profissionalização docente. Projeto Integrado de Pesquisa Profissionalização e Gerencialismo na Educação. Departamento de Estudos Especializados em Educação do
Centro de Ciências da Educação e do Programa de Pós-graduação em Educação da Universidade Federal de Santa Catarina, 2004. Mimeografado.

SEN, Amartya. Desigualdade reexaminada. Rio de Janeiro: Record, 2001.

STIGLITZ, Joseph. A globalização e seus malefícios: a promessa não-cumprida de benefícios globais. 4. ed. São Paulo: Futura, 2003.

THOMAS, Vinod. Os avanços sociais no Brasil. Folha de S. Paulo, São Paulo, 24 jun. 2002.

UNESCO. Década das Nações Unidas da Educação para o Desenvolvimento Sustentável (2005-2014). Documento Final Plano Internacional de Implementação. Brasília: Orealc, Unesco, 2005.

Recebido em 04/08/2008

Aprovado em 18/09/2008 
